\title{
Web mapping platform for spatial monitoring of projects in the urban sector: the case of Cameroon
}

\author{
Clarice Fotso, Landry Engelbert Tongo \\ National Institute of Cartography, Cameroon
}

\begin{abstract}
The urban sector is a critical sector for the coming decades with the growth of the urban population. It is therefore important to guarantee investments, with optimal monitoring of projects. In Cameroon, this activity is the responsibility of the Ministry of Housing and Urban Development, which has specially set up a web application to monitor these projects. However, this platform remains limited because it does not exploit the spatial component of the projects. In this article we propose a cartographic web platform for the spatialized monitoring of projects in this sector for Cameroon. The implementation of this platform followed the steps of a software development process. The result is a cartographic web application that offers an interactive thematic map for monitoring projects in the urban sector. The base maps available, in particular the OSM map and the Google satellite image, as well as the interactivity offered through cartographic navigation and querying the project layer, provide better visibility on the real progress of projects on the site.
\end{abstract}

Keywords: web mapping, urban sector, project monitoring, voluntary geographic information, decision support tool.

\section{INTRODUCTION}

A ccording to the World Bank, 55\% of the world's population, or 4.2 billion people, live in cities and this trend will continue by 2050 . With the doubling of the current number of city dwellers, almost 7 in 10 people around the world will live in urban areas. To control this urbanization, policies must be able to respond to a number of challenges, including the increasing demand for affordable housing, wellconnected transport networks and other essential service infrastructure. Building these "functional" cities, that is inclusive, healthy, resilient and sustainable, requires intense efforts to coordinate policies and make smart investment choices. It is imperative that national and local authorities take action now to prepare for the future development of cities and create opportunities for all [9].

In Cameroon this mission is devolved to the Ministry of Housing and Urban Development (MINHUD) [10], which is responsible for formulating and implementing government policy on housing and urban development. In fulfilling its mission, the MINHUD realizes every year various projects that cover matters such as the development of roads, urban sanitation, construction of social housing, etc... For better management of these crucial projects, MINHUD has a web platform that allows it to monitor the progress of the execution of these projects. It is a decision support tool that provides in table format, information by city, on projects planned, carried out or in progress with their administrative, technical and financial descriptions, as well as their advancement level. However, for the monitoring of spatial reference projects, this mode of presentation is limited for a better reading of the decision-maker because some additional decision-making information is not available, the occurrence of an overview of the real evolution of the work in the field., the spatial distribution of projects, and possibly an overview of the impact of projects carried out in the field.

On the other hand, the map, which is a representation of geographical space [3], offers a synoptic view of an event too large to be understood physically [2]. It is therefore an intelligent technology which makes it possible to visualize together and simultaneously a large number of elements with the possibility of including different elements and to compare them [2]. With the technological evolutions of the web, online cartography now offers wide possibilities to any Internet user. The retrieval of geographic information ranges from classic forms of static maps, to more interactive, dynamic and animated maps. These current web technologies thus make it possible to set up cartographic applications with excellent capabilities for displaying and manipulating data (fluidity, pleasant navigation, intuitive change of scale, etc.) [1]. In this article we propose to set up a web mapping application for the spatial monitoring of MINHDU projects across the national triangle. This type of tool has the advantage of a graphical presentation, as graphics increase the efficiency of the communication process; they have a virtue of synthesis allowing the reader to easily absorb a large amount of information [2]. The objective is to improve the quality of monitoring of urban sector projects in Cameroon, in order to improve compliance with deadlines and the use of the financial resources dedicated to them.

\section{METHODOLOGY}

Software engineering represents the application of engineering principles to the field of software creation. It consists in identifying and using the methods, practices and tools to maximize the chances of success of a software project [5]. The development process of this web mapping application took place in five (05) stages following the waterfall model: Existing and needs analysis, requirements specifications, design, implementation and testing. 


\section{A. Analysis of existing and requirements}

The purpose of this first phase of the process is to collect the user's requirements. It was done from interviews with target MINHUD staff, in order to understand the field, understand the functioning of the existing project monitoring platform and in order to collect user needs.

\section{B. Requirements specifications}

The requirements collected from the client are written in natural language. This phase therefore aims to document the requirements in a technical language so that they can be understood and useful for the design [4]. To do this the UML language was used.

\section{Design}

Design is a process of transforming user needs into an appropriate form, which helps code and implement software [4]. In terms of architectural design, the MVC (Model-ViewController) architecture mainly used in web applications was chosen [6].

Regarding the detailed design, a mock-up was made at the view level. For control or processing, a function-oriented approach was used with the definition of the design diagram for each of the functionalities identified in the analysis. As for the model which refers to the data, the conceptual model of the existing data has been modified in order to integrate the spatial reference of the projects.

\section{Implementation}

The activities of this phase consisted of:

- Deploy the architecture of the application, by installing the components;

- Create the database according to the defined model and insert the existing data;

- Configure the map server by setting mapfile;

- Write the lines of code following the design diagram defined for each functionality.

\section{E. Tests}

Software testing is an assessment of software against requirements gathered from users and against system specifications [4]. This phase mainly aims to identify:

- Coding errors;

- Faults, which result from an error that can cause the system to fail;

- Failure, the inability of the system to perform the desired task.

\section{RESULTS}

The main requirements that result from the analysis are presented as follows:

1. The display of projects on the map: for a given period, by default it is the current year. This display consists in presenting on the base map of Cameroon which can run under OSM [7] or Google [8], the cities in which there are projects, in the case where the display scale is small or directly the projects in progress in the territory, in the case where the current scale is large.

2. Access to descriptive information on cities with projects as well as on projects displayed on the map. The descriptive information on a city with projects concerns:

- The total number of projects in this city, for the given period;

- The list of projects in the city, with possibility to access descriptive information (administrative, financial and technical) of them, and their level of advancement.

3. The multi-criteria search: it aims to carry out searches according to a set of criteria to refine a search. These criteria relate to:

- The structure in charge of the project;

- $\quad$ The project award procedure;

- The Funding sources;

- The field of the project (housing, sanitation, roads, supplies, etc.);

- The programs (C2D, emergency plan, etc.);

- The year (fiscal year);

- The level of execution (attribution, closed, reception, etc.).

These requirements are summarized in the following use case diagram:

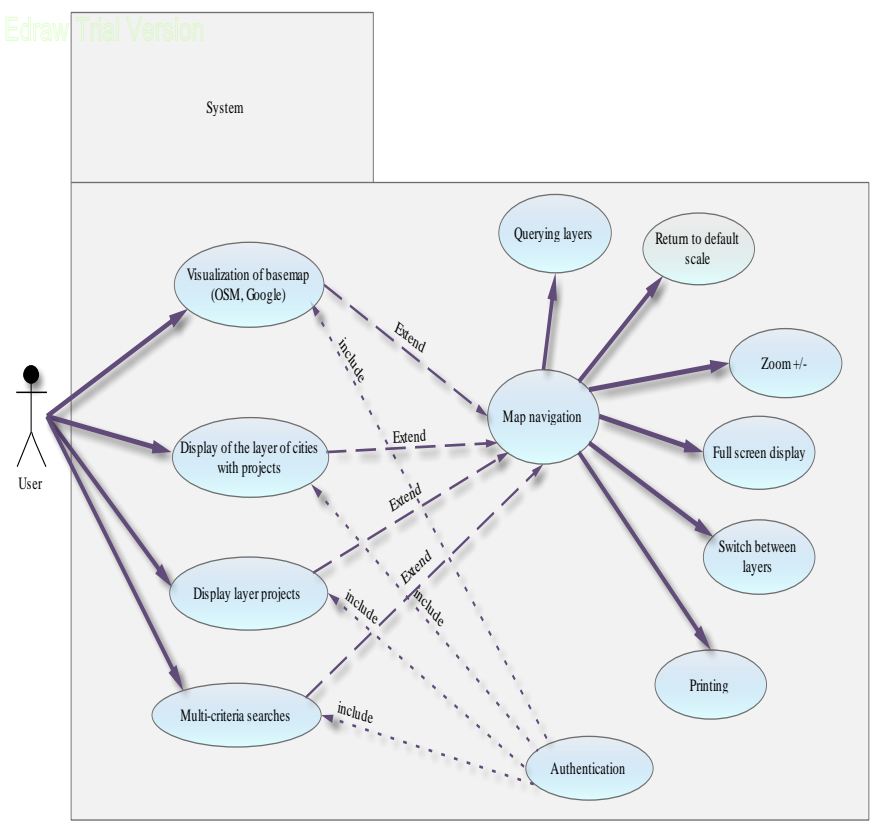

Figure 1: Diagram of the use cases of the platform

In terms of design, the general architecture which technology choices have focused on open source confirmed, is as follows: 


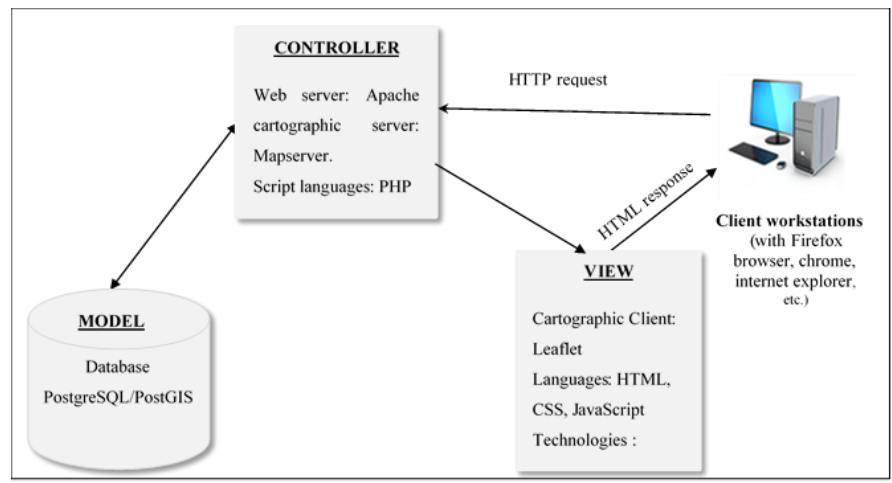

Figure $2:$ Software architecture of the platform

The resulting application looks like this

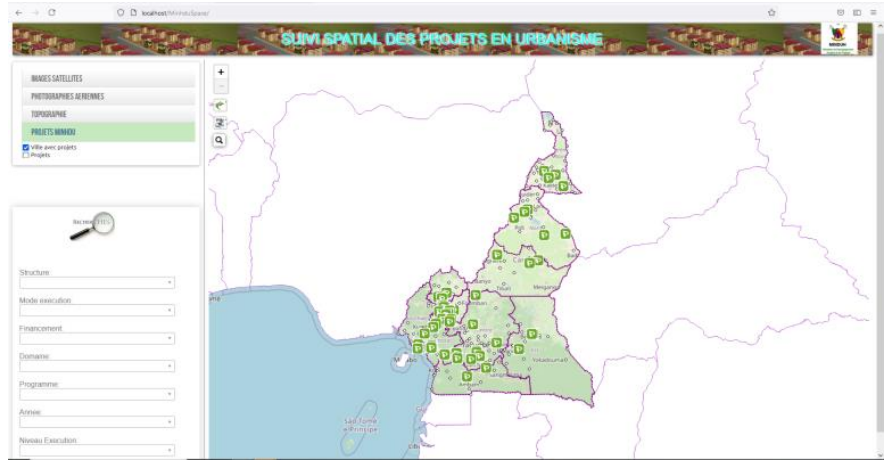

Figure 3:_Home page, by default the OSM base map

The application is an interactive thematic map, which uses the OSM base map by default, but the user can switch to the Google satellite image as the base map at any time.

On a small scale (country scale $1 / 500,000$ for example), the thematic map covers the cities in which there are projects for the given period (by default the current year). When the user clicks on a City-Project, $P$ it gets the number and the list of projects that exist in this city.

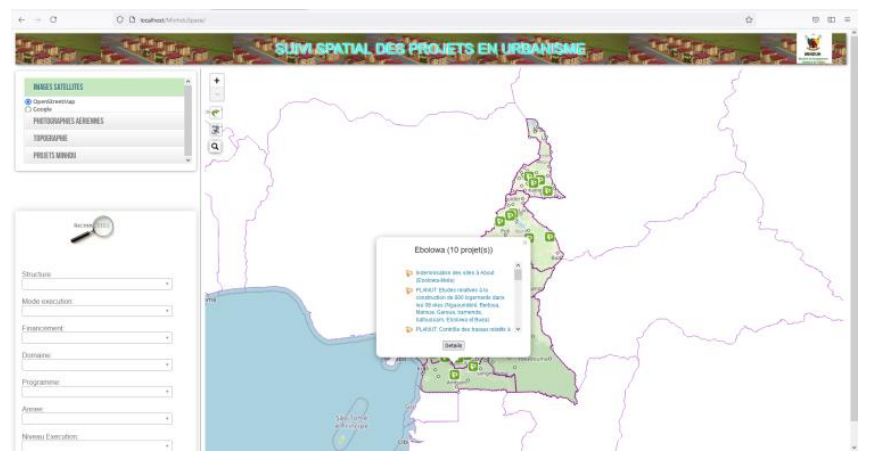

Figure 4: Example of a description of a City-Project

For each project appearing in the list, a description of the latter can be obtained by clicking on the identified project. This description provides administrative, financial and technical information on the project, as well as monitoring indicators, such as the completion rate, the payment statement, etc.

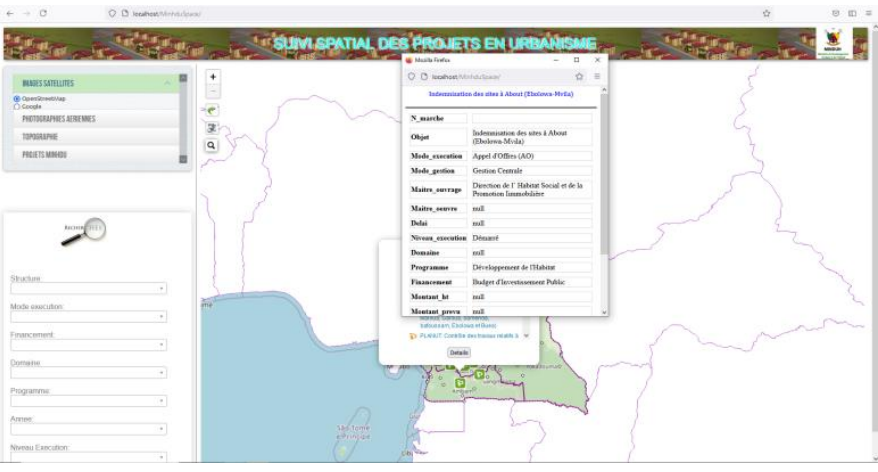

Figure 5: Display of a project description

On a large scale (scale of the city $1 / 5000$ for example), the thematic map relates directly to the projects. When the user clicks on a project, he gets the project description.

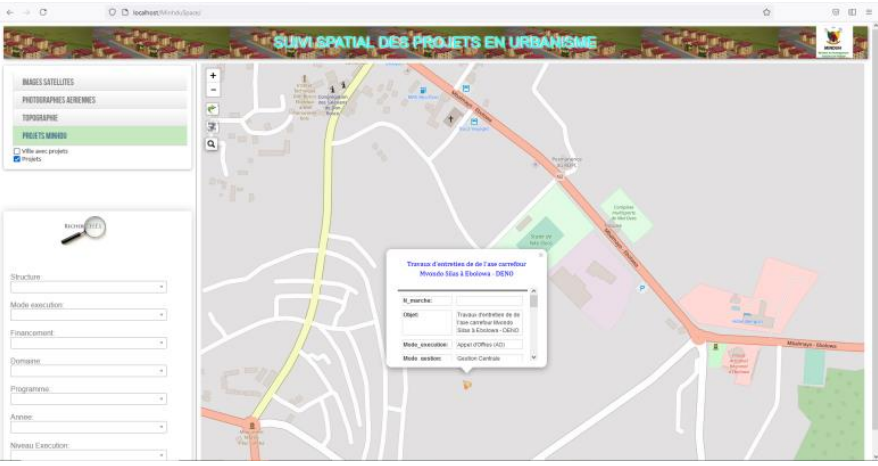

Figure 6: Display of a project on an OSM base map

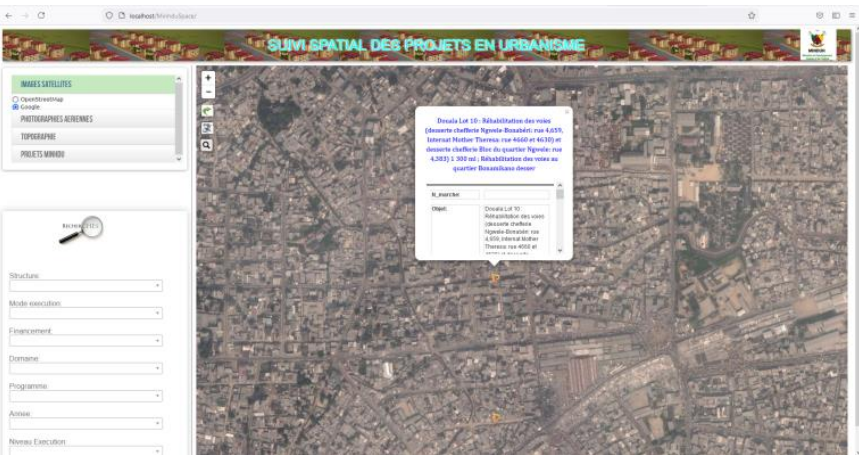

Figure 7: Project on a Google satellite image as base map

\section{DISCUSSION}

The proposed web cartographic platform enables decisionmakers in the urban sector to carry out spatial monitoring of projects. Indeed, the information display mode is a thematic map in which the project is represented in its real space. The base maps available, namely the OSM map, which is the result of the voluntary collection of geographic information, is changing rapidly, particularly in Cameroon, where there is a fairly dynamic OSM community. Also the Google satellite image base maps is regularly updated. All these base maps in addition to those that could be added (Bing, Esri, etc.) provide additional information to the decision-maker for a better 
appreciation of the progress of the work in the field, even if it remains necessary to go down there to precise checks. This platform therefore enriches the monitoring of projects in the urban sector, which was done in the past, based on simple digital or textual information. This additional spatial information makes it possible to better understand the evolution of the project in its space, but also to have an idea of the impact of the project through the evolution of the environmental space.

However, several other enrichments could be made. First of all, the integration of a dashboard aspect into the spatial presentation of projects. This would quickly give a better synoptic view of the evolving situation of projects by region, department and city. Also, the planning assistance component with spatial analysis functions could be integrated. Indeed, the enrichment of the database with other existing data such as housing, water points, road network, health facilities, etc. would make it possible to carry out spatial analyzes to optimally guide the decision-maker in choosing the location of new urban planning projects. Example health facilities that are not served by a road in good condition, populations without drinking water point at a certain distance, etc.

\section{CONCLUSION}

The purpose of this article was to present a cartographic web application for the spatial monitoring of projects in the urban sector. Its implementation took place in five (5) stages: requirements gathering, functional specifications, design, development and testing. The collection of requirements was based on interviews with officials in this sector in Cameroon, as well as a study of the already existing monitoring application. An analysis of the information collected made it possible to formally specify these requirements. Following the design, the platform was implemented from components Apache, Mapserver, PostgreSQL, and Html, JavaScript, PHP languages. The results obtained present a platform which runs under an OSM map and Google satellite image as base maps, according to the user's choice and allows to display at a certain scale the cities with projects and their descriptions which gives a summary of the number of projects as well as the list. of these projects with the possibility of obtaining the descriptive or evolving detail of each of these projects. It is also possible from a large scale to have direct access to the location of the project and their information. The multi-criteria search is also available to refine the search for projects according to certain criteria. At the end of this work, the platform brought more to the decision-maker in his project monitoring tasks, however it could still evolve with the integration of the dashboard or spatial analysis component to better orient investments

\section{REFERENCES}

[1] Boris Mericskay and Stéphane Roche (2011). "Cartography 2.0: the general public, producer of geographic content and knowledge with web 2.0". Cybergeo: European Journal of Geography [Online],

ScienceetToile,document552,DOI https://doi.org/10.4000/cybergeo .24710 .

[2] Jean-christophe plantin (2014). Online mapping. Google book.

[3] https://www.techno-science.net/definition/2564.html.

[4] Raphael Yende (2019). Software engineering course Part 2. Master. Congo-Kinshasa. Cel-02116792

[5] Baptiste Pesquet (2017). Introduction to software engineering. Developpez.com. July 2017

[6] Modelviewcontroller.EncyclopédieWikipédia,https://www.en.wiki pedia.org/wiki/Model-view-controller Last accessed 25 may 2021.

[7] OSM Homepage, https://www.openstreetmap.org /. Last accessed 25 may 2021

[8] Google Homepage, https://earth.google.com/web/ . Last accessed 25 may 2021

[9] WorldBankHomepage,https://www.banquemondiale.org/fr/topic/ur bandevelopment/overview, Last accessed 02 June 2021.

[10] MINHUD Homepage, http://www.mindhu.gov.cm , Last accessed 02 June 2021 